\title{
The EU and the OECD: How a closer relationship could be a winner
}

Written by: Philip Pierros, Minister-Counsellor and Deputy Permanent Representative, EU Delegation to the OECD

Last update: 28 January 2020

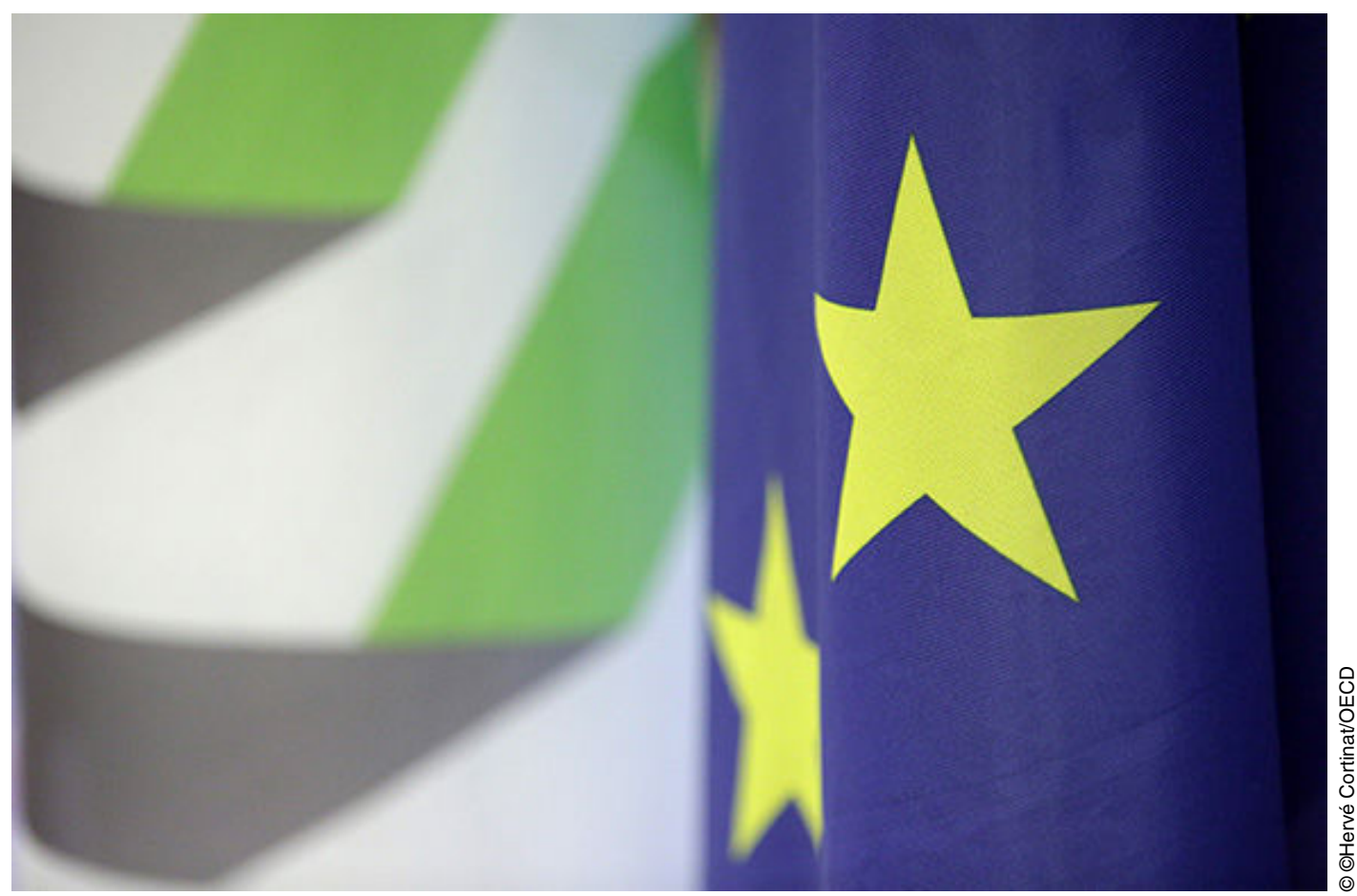

The EU and the OECD: How a closer relationship could be a winner I Image for The EU and the OECD: How a closer relationship could be a winner

Hecate is one of Greek mythology's many intriguing goddesses. A three-headed character, she is associated with sorcery, but also with boundaries and walls, as well as crossroads, entranceways, gates and doorways, and lights. She is depicted carrying torches and keys, so that while some historians see Hecate as a protector who bestows prosperity, others compare her to the Roman Janus, a symbol of openings and new beginnings, able to light the way ahead. 
How Hecate's torches and keys could help us now as we face today's crisis in international co-operation! Never in our lifetimes has the global order, which was built painstakingly over half a century from the ashes of two brutal world wars, looked so fragile. Rising populism on all continents, recourse to nationalism across the Atlantic and rifts within the European Union (EU) have all fuelled a run from globalism and a rush for protection.

As a measure of how serious this is, French President Emmanuel Macron warned world leaders gathered in Paris on 11 November 2018 to mark the centenary of the end of the First World War of the dangers of backsliding towards destructive nationalism. The president senses a chill wind. Indeed, a front page of the normally calm French daily, Le Monde, headlined: "US-Europe: The story of a divorce" (Etats-Unis-Europe: histoire d'un divorce, samedi 10 nov). The editorial of the same edition appealed for action to save world governance (see references).

We are all at a crossroads, with a national, inward looking path beckoning in one direction, and a global, multilateral route in the other. To my mind the choice is clear: the only way forward is for countries to work harder than ever multilaterally, through institutions such as the EU and the OECD.

The trouble is, too many people question their legitimacy. The EU is faced with the upending effects of Brexit and regrettably certain other centrifugal forces pulling it in different directions; meanwhile, the OECD faces a difficult budgetary climate, and the constant challenge of instilling a clear sense of purpose among its sometimes sceptical members. How the world has turned on its head, as the UK and the US, which both championed outreach and globalisation for over 50 years, should turn inwards now. No wonder people, just like the three-headed Hecate, are looking in every direction for an answer.

Could Hecate hold a key by pointing to a third way? Even the most ardent of globalists would acknowledge that the multilateral system, as it currently stands, needs some fixing to be more relevant in people's lives. Hence my suggestion: to consider a formal rapprochement between the EU and the OECD.

Is this fantasy? After all, on the face of it there are so many differences. The OECD uses data, analysis and its federating power to coax its members to pursue better policies for better lives. It has few legally binding conventions, and relies on peer pressure to nudge all countries to do ever better. It has no parliament, but is governed by a web of committees and a ministerial council that reports to capitals.

Though 23 of the OECD's 36 countries are EU member states, the EU is a more powerful entity, with its decision-making European Council run by member governments, its Commission and European Parliament, and its central bank and legal courts. It is a union where nations pool their sovereignty together, notably to support the single market and other relevant common policies. 
But the EU nevertheless looks to the OECD for guidance, analysis, expertise and support, and is in fact very actively involved in the OECD, albeit without contributing to the regular budget-the EU is nevertheless among the top providers of voluntary contributions to the OECD-or being able to vote on legal acts. Could this evolve? Are there complementarities to develop further? Could the relationship be put on a stronger, more systematic and institutionally more robust basis?

The answer in my view is yes. Here are five reasons why the OECD and the EU should work more closely together:

First, a closer relationship would strengthen and cement the multilateral cooperation and global governance that are so critical for the future of a peaceful and prosperous world order;

Second, it would help us better address global challenges, such as the UN Sustainable Development Goals and climate change, by setting ambitious common standards and benchmarks with an enhanced legitimacy;

Third, it would help boost trade and better stem protectionist tendencies;

Fourth, it would bolster the EU's efforts in addressing structural challenges by mobilising and leveraging OECD expertise, and so help EU member states implement structural policy recommendations, such as investing in skills and integrating migrants, or enhancing productivity and fostering a more sustainable "circular" economy;

And fifth, a closer arrangement would enhance the political legitimacy and attractiveness of the OECD on the world stage, helping it to brush off its backoffice image and engage more with the public, while enhancing the EU's own global network and outreach.

One question mark arising from a closer relationship would be the extent to which OECD members that are not in the EU, particularly the major ones like the US and Japan, might influence EU affairs, but in my model the OECD would act strictly as a consultant, with no right to participate in internal EU decisionmaking. However, an EU contribution to the OECD budget could be considered.

Building a closer EU-OECD relationship would require courageous, out-of-the-box thinking, not to mention a strategic high-level agreement. But it could eventually lead to a template for other international organisations to follow, with wins for the multilateral approach more broadly. Our state-centric system has long overlooked the power, legitimacy and norm-setting potential of certain "sovereign" international and regional organisations. Engaging with them on a more systematic basis cannot but consolidate multilateralism. The EU is admittedly a global actor that falls into this category.

We are at a Hecate-like crossroads and bold decisions are needed. We have a chance to safeguard the rules-based global order, even if we must reform it and 
build a new, stronger multilateral system. A closer EU-OECD relationship could be a step in the right direction.

*The views expressed in this article are strictly the author's only, and do not purport to reflect the views of the EU, the OECD or any of their members.

COOECD Observer Q4 2018

\section{References}

http://arcana.wikidot.com/hecate http://arcana.wikidot.com/hecate

https://www.patheos.com/blogs/adamantinemuse/2018/01/hekate-zeus-janus/ https://www.patheos.com/blogs/adamantinemuse/2018/01/hekate-zeus-janus/ see www.oecdobserver.org see www.oecdobserver.org 